University of Nebraska - Lincoln

DigitalCommons@University of Nebraska - Lincoln

\title{
Climate suitability and human influences combined explain the range expansion of an invasive horticultural plant
}

\author{
Carolyn M. Beans \\ University of Virginia, carolynbeans@email.virginia.edu \\ Francis F. Kilkenny \\ US Forest Service, ffkilkenny@fs.fed.us \\ Laura F. Galloway \\ University of Virginia, Igalloway@virginia.edu
}

Follow this and additional works at: https://digitalcommons.unl.edu/usdaarsfacpub

Beans, Carolyn M.; Kilkenny, Francis F.; and Galloway, Laura F., "Climate suitability and human influences combined explain the range expansion of an invasive horticultural plant" (2012). Publications from USDAARS / UNL Faculty. 1232.

https://digitalcommons.unl.edu/usdaarsfacpub/1232

This Article is brought to you for free and open access by the U.S. Department of Agriculture: Agricultural Research Service, Lincoln, Nebraska at DigitalCommons@University of Nebraska - Lincoln. It has been accepted for inclusion in Publications from USDA-ARS / UNL Faculty by an authorized administrator of DigitalCommons@University of Nebraska - Lincoln. 


\title{
Climate suitability and human influences combined explain the range expansion of an invasive horticultural plant
}

\author{
Carolyn M. Beans • Francis F. Kilkenny • \\ Laura F. Galloway
}

Received: 1 April 2011/Accepted: 29 March 2012/Published online: 10 April 2012

(C) Springer Science+Business Media B.V. 2012

This article is a U.S. government work, and is not subject to copyright in the United States.

\begin{abstract}
Ecological niche models are commonly used to identify regions at risk of species invasions. Relying on climate alone may limit a model's success when additional variables contribute to invasion. While a climate-based model may predict the future spread of an invasive plant, we hypothesized that a model that combined climate with human influences would most successfully explain its present distribution. We used the ecological niche model MaxEnt to test our hypothesis with Japanese honeysuckle (Lonicera japonica), a common invasive horticultural plant in the United States. We first predicted the future range expansion of the species in the United States using a model that was trained on the climate conditions in its native range. We then tested the ability of a climate-based model, which
\end{abstract}

Electronic supplementary material The online version of this article (doi:10.1007/s10530-012-0214-0) contains supplementary material, which is available to authorized users.

C. M. Beans $(\bowtie) \cdot$ F. F. Kilkenny · L. F. Galloway

Department of Biology, University of Virginia,

P.O. Box 400328, Charlottesville, VA 22904-4328, USA

e-mail: carolynbeans@email.virginia.edu

F. F. Kilkenny

e-mail: ffkilkenny@fs.fed.us

L. F. Galloway

e-mail: lgalloway@virginia.edu

Present Address:

F. F. Kilkenny

USDA Forest Service, Pacific Northwest Research

Station, Corvallis, OR, USA was trained on climate conditions in the invaded range, to predict the current distribution in the United States. Finally, we tested whether including a measure of human influence would improve this model. Our results indicate that, despite L. japonica's 200-year invasion history, it is expected to spread beyond its current US range. Climate and human influence combined explain the current distribution. Modeling the spread of invasive horticultural plants using climate alone risks underpredicting areas with poor climates and high human influence. Therefore, planting invasive horticultural species should be discouraged as even suboptimal climates may result in further range expansion.

Keywords Lonicera japonica - Invasive species . Human footprint · Range expansion . Ecological niche model · Horticultural industry

\section{Introduction}

Invasive species continue to spread and threaten biodiversity on a global scale (Lodge 1993a, b). There is a growing need, therefore, to identify areas that are at a high risk of invasion, and monitor these sites to prevent further incursion. Ecological niche models are valuable tools for designating these high-risk regions. They have proven valuable in predicting the geographic expansions of a broad range of species, particularly the spread of invasive plants (Peterson and 
Robins 2003; Peterson et al. 2003; Drake and Bossenbroek 2004; Dunlop et al. 2006; Wang and Wang 2006; Ficetola et al. 2007; Urban et al. 2007; Pattison and Mack 2008; Kadoya et al. 2009). These models are frequently used to project the potential geographic distribution of a species by matching the climate conditions found in the native range with suitable climates at a potential site of invasion (Phillips et al. 2006). These climate-based models rely heavily on the Grinnellian niche concept, which assumes that a suitable climate is a necessary prerequisite for range expansion (Guisan and Thuiller 2005). This ecological niche modeling approach can be useful for focusing conservation efforts to monitor only those regions with suitable climates, while ignoring areas where, even if introduced, it is believed the invasive species would not survive.

Climate, however, is not the only force guiding the geographic spread of species invasions. Invasive species distributions are frequently associated with humans (McKinney 2001; Sullivan et al. 2004; Pyšek et al. 2010). This association is expected to be especially strong when the species is actively spread and cultivated by people, as is the case for many invasive horticultural plants. Humans may contribute to a plant invasion by increasing propagule pressure through garden plantings and offering opportunities for establishment through land disturbances (Lockwood et al. 2005; DehnenSchmutz et al. 2007; Pyšek et al. 2010). The presence of humans, therefore, may increase the likelihood of establishment, even in areas with suboptimal climates (Richardson et al. 2010). It is possible, then, that niche models based on climate alone may underestimate the probability of establishment in areas with high human influence, which would hinder our ability to identify areas at risk of invasion (Ficetola et al. 2007; Richardson et al. 2010; Roura-Pascual et al. 2011). Additionally, if the current distribution of an invasive horticultural species depends on human influence, then efforts to prevent the further spread of the species must be geared towards not only limiting spread into climatically suitable regions, but discouraging plantings in any climate.

We investigated the connection between humans and invasive species range expansions through our assessment of the distribution of the invasive horticultural plant, Japanese honeysuckle (Lonicera japonica) in the United States. We first used a climate-based ecological niche model to predict the potential future spread of $L$. japonica in the United States based on where climate conditions in the invaded range match the climate of its native territory. Then, because of its 200-year history as a horticultural plant, and its ability to spread opportunistically in disturbed areas, we hypothesized that human influence may have contributed to the current United States range of this species (Schierenbeck 2004). We used ecological niche models trained on the United States to test whether adding a measure of human influence to the climate-based model significantly increased our ability to predict the current distribution. Our findings indicate that $L$. japonica, despite its long residence, will likely expand to the west and north of its current US invaded range. In addition, we found that an introduced-range climate-based model, while accurately predicting the presence of $L$. japonica across the vast majority of the invaded United States range, under-predicted the presence of populations in areas with low climate suitability and high human influence. Adding a measure of human influence to the model significantly increased our ability to predict the current distribution of L. japonica in the United States.

\section{Materials and methods}

\section{Study system}

Lonicera japonica Thunb. (Caprifoliaceae) is a perennial vine native to Japan, China and Korea, that invades natural and managed habitats throughout the United States and worldwide (Schierenbeck 2004). L. japonica was first introduced to Long Island, New York in 1806 (Leatherman 1955; Nuzzo 1997). Throughout the nineteenth century several horticultural varieties were introduced and widely planted in gardens across the United States, where it was prized for its scented flowers, long blooming period, and ability to grow in both full sun and full shade (Leatherman 1955). While it remains a popular horticultural plant today, L. japonica is now considered a major pest by the forestry industry, as well as state and federal governments, and is banned for horticultural sale in several states (Dillenburg et al. 1993; Skulman et al. 2004; USDA 2009). Among its most damaging qualities is its ability to form dense mats and outcompete native vegetation for both light and nutrients (Hardt 1986). The range of L. japonica 
now covers most of the eastern portion of the US, with plants growing as far west as Texas and the eastern edges of Oklahoma and Nebraska, and as far north as New England. It is also found scattered more sparsely across the western US.

Once naturalized in the late 1800 s, L. japonica demonstrated rapid range expansion, and by 1955 had encompassed much of its present day range (Leatherman 1955; Nuzzo 1997). An analysis of the 2006 northern edge of the range showed that the distribution has continued to advance northward beyond the 1955 edge, although at a slower rate than demonstrated during the first 50 years since naturalization (Kilkenny 2011). This decrease in invasion speed suggests that $L$. japonica may be reaching the edge of its fundamental niche in the northern United States. The fact that spread is still occurring into new climates in the north, however, suggests that it is possible that the range may still be advancing into new climates at other edges of its distribution, such as in the western United States. The western edge of the range was not well documented, so the rate of spread in this region is unknown. After 200 years of invasion, it is unclear whether L. japonica has filled its entire niche space in the United States.

Ecological niche model

We used MaxEnt version 3.3.3, an ecological niche model, to predict the future range expansion of $L$. japonica in the United States, and to identify whether human influence is responsible for its current US distribution (Elith et al. 2011). MaxEnt is a machine learning tool that uses a general purpose algorithm to estimate a suitability index for a species across a defined geographic space based on environmental parameters and point locality data from within the species' known range (Phillips et al. 2006). Using the principle of maximum entropy, the model accepts all given locations of the species as representing true presence points, but does not assume that locations without presence data represent species absences (Phillips et al. 2006). Therefore, the model only requires presence data and does not require information on where the species is absent. MaxEnt has proven successful in the modeling of invasive species range expansions (e.g. Hernandez et al. 2006; Ward 2007; Phillips 2008). We fit all models using the default settings for output, feature type, and regularization for MaxEnt version 3.3.3.
Data collection

MaxEnt requires geographic coordinates representing the species' presence. The native range of L. japonica includes China, Japan, and South Korea. We obtained location data for these countries online from the Chinese Virtual Herbarium and the Global Biodiversity Information Facility (see Table S1 in Supporting Information). To obtain location data for the United States range, we constructed a dataset of $L$. japonica presence points using direct collections, herbaria records, and online resources such as the Global Biodiversity Information Facility, EDDMapS, and the Consortium of California Herbaria (see Table S1). To our knowledge, all of these presence points represent wild populations of $L$. japonica.

For a substantial portion of our location coordinates in China and the United States, the finest scale geographic information available was limited to the county level. Therefore, for these countries, we found the centroid of each county where a minimum of one L. japonica specimen was collected and used these coordinates as presence data. Counties in Japan and South Korea are much smaller than in the United States and China. Therefore, in order to maintain the same scale of sampling across all countries, we found the centroid of prefectures in Japan and provinces in South Korea where L. japonica is present and used these coordinates as presence data.

We wanted to ensure that centroids accurately reflect the climate conditions experienced by $L$. japonica, given the large amount of elevational variation found in some parts of the native range. For a subset of our data, just those presence points found within China, we ran models using the highest or the lowest elevation points in each county as presence points and compared them to a model that used centroids. All three models predicted equivalent distributions (results not shown), indicating that it is appropriate to use the centroid of each county to approximate the climate conditions experienced by L. japonica within that county as a whole.

Using the centroid of counties as presence points allowed us to ensure that no presence point was duplicated in our dataset. This method may, however, have lead to some degree of sampling bias in the United States. More presence points were drawn from regions of the country with smaller counties. In the west, counties tend to be larger and, therefore, could 
not have produced as many presence points even if $L$. japonica was very common there. Still, because $L$. japonica actually is less common in the west, this bias is expected to have minimal impact on our model. The centroids were calculated using ArcGIS version 9.3.1 (ESRI, Redlands, CA, USA). This technique yielded 192 presence points in Asia and 1,561 presence points in the United States.

In addition to species presence data, MaxEnt also requires data on environmental conditions. We obtained climate data at the scale of 10 arc minutes from WorldClim version 1.4, a global climate database available online (Hijmans et al. 2005). WorldClim's climate data come in the form of 19 bioclimatic variables derived from monthly temperature and precipitation values. We also obtained an additional variable, the human footprint. The human footprint is an index of human impact on landscapes, and is available online (Sanderson et al. 2002). Factors such as population density and land transformation contribute to the human footprint index (Sanderson et al. 2002). This variable was used to test the association between humans and the distribution of L. japonica in the United States. We also tested whether the human footprint was correlated with any of the climate variables used in our analysis by extracting the human footprint and climate values for each grid cell within the United States and performed a correlation analysis with this data. We found that the human footprint is not highly correlated with any climate variables in the United States (all $R$ values $<0.5$, see Table $\mathrm{S} 2$ ).

\section{Predicting future US range expansion}

In order to predict the future range expansion of L. japonica in the United States, we began by training a model on its native range. This model was trained on presence data from the native range and a background that included the full geographic extent of China, Japan, and Korea (Figure S1). The model relied upon two bioclimatic variables, mean temperature of coldest quarter and precipitation of warmest quarter. We selected these variables from the 19 available bioclimatic variables based on our understanding of the climatic requirements of the species. Two common garden experiments showed that winter temperatures and summer drought conditions greatly impact L. japonica survival (Kilkenny 2011).
We tested the strength of the model by projecting the predicted distribution back onto the native range. Model strength was quantified using the area under the curve (AUC) of the receiver operator characteristic generated within MaxEnt (Phillips et al. 2006). For validation purposes, a random sample of $25 \%$ of the presence data was reserved for testing the model. The remaining $75 \%$ of presence points were used as training data for building the model. The AUC values of models using the training data and the test data were compared.

After assessing the accuracy of this native rangetrained model, we then used it to project the potential distribution in the United States. By training the model on the native territory, we expected to capture most potential climates suitable for the species. In contrast, training the model on the invaded territory may miss suitable climates if the species has not yet encountered them and, therefore, may underestimate the potential range of the species (Phillips 2008). The recently documented range expansion of $L$. japonica in the United States suggests that the current range may not yet extend into all suitable climates, so training the model on the native range is appropriate (Kilkenny 2011). We did not include the human footprint in the native range-trained model. Because $L$. japonica is not cultivated as a horticultural plant in Asia (D. Boufford 2011, personal communication), there is no reason to assume an association with humans.

One of the basic assumptions of ecological niche modeling is that the range of each environmental variable in the projected region falls within the range covered by the training data. MaxEnt employs clamping to restrain variables to this range. If variables in reality fall outside of this range, then predictions based on this model become difficult to interpret and perhaps even erroneous. In order to inform users whether this issue is present, MaxEnt offers maps that illustrate where clamping occurred, as well as MESS maps that show where environmental variables fall outside the range present in the training data (Elith et al. 2011). Using these tools, we found that clamping did not impact our projection and neither variable fell outside the range present in the training data.

We tested the agreement between the projected potential distribution and the current range of $L$. japonica in the United States using a logistic regression. This analysis compared the presence or absence 
of L. japonica in each US county to the predicted environmental suitability for that locality. This analysis tests the ability of our model to predict the current range of L. japonica in the United States. However, it does not directly test how well our model predicts the potential range of $L$. japonica in the United States. Because $L$. japonica is likely still spreading, it may be absent from a region either because the climate hinders establishment, or because the plant has not yet dispersed there. The latter case will result in disagreement between our model and absence records in high suitability areas. After 200 years of expansion, L. japonica likely fills a large portion of it's potential range so the prevalence of these disagreements should be minimal. Testing how well a model explains the current distribution, therefore, is a suitable proxy for how well the model predicts the potential for L. japonica presence.

In addition to our statistical analysis, we visually compared the predicted distribution from the native range-trained model with the current distribution from our United States range map to identify regions where further expansion is likely.

Identifying variables responsible for current US distribution

We used MaxEnt to test whether climate variables alone predict the current distribution of L. japonica in the United States. We hypothesized that human influence would increase our ability to predict $L$. japonica presence in areas of low climate suitability because our native range-trained model that was based on climate variables alone under-predicted the presence of $L$. japonica in urban areas in the western United States (see "Results"). We first trained a model using all 19 climate variables and all $L$. japonica presence points on a background that included the full geographic extent of the continental United States in order to assess how well these climate variables explain the current United States distribution. This model is useful for identifying which climate variables contribute to the current distribution of L. japonica in the United States, but is not appropriate for predicting further range expansion. Because L. japonica is likely still spreading, there may be climates suitable for establishment that have not yet been reached.

We then created another model in MaxEnt using the human footprint to determine whether human influence contributes significantly to $L$. japonica presence in the United States. Finally, we constructed a full model, which included United States presence points, all climate variables, and the human footprint. We used logistic regression to test the ability of each of the models to predict the current distribution of $L$. japonica. We then used log-likelihood ratios to test whether the US-trained model that combined the human footprint with climate variables was significantly stronger than either the climate-based or the human footprint-based models alone.

We identified the variables in our full model most capable of predicting L japonica presence using three tests generated by MaxEnt. The jackknife analysis tested the predictive power gained by each variable alone. The relative contribution of each variable was estimated by calculating the percent contribution of each variable during the model training process. Finally permutation importance was estimated as the relative loss in AUC value of the final model when the values of a given variable are randomly permuted among the presence points and random background points. Higher percent permutation importance means greater relative loss in AUC value after random permutation, and, therefore, greater reliance on the variable (Phillips 2010).

Finally, we tested whether the human footprint variable uniformly improved the predictive power at all presence points or whether it impacted the model differently in areas of low versus high climate suitability. We calculated the difference between the suitability values predicted between the full model and the climate-based model across the range of climatebased suitability values. Because we found that the human footprint increased our ability to predict $L$. japonica primarily in regions with a climate suitability value below 0.45 (see "Results"), we used a paired $\mathrm{t}$-test to assess whether this increase in predictive power in under-predicted areas was statistically significant. All statistical analyses were conducted in SAS version 9.2 unless otherwise noted (SAS Institute, Cary, NC, USA).

\section{Results}

Predicting future US range expansion

The native range projected by MaxEnt closely matched the known native range. The model projected 
A

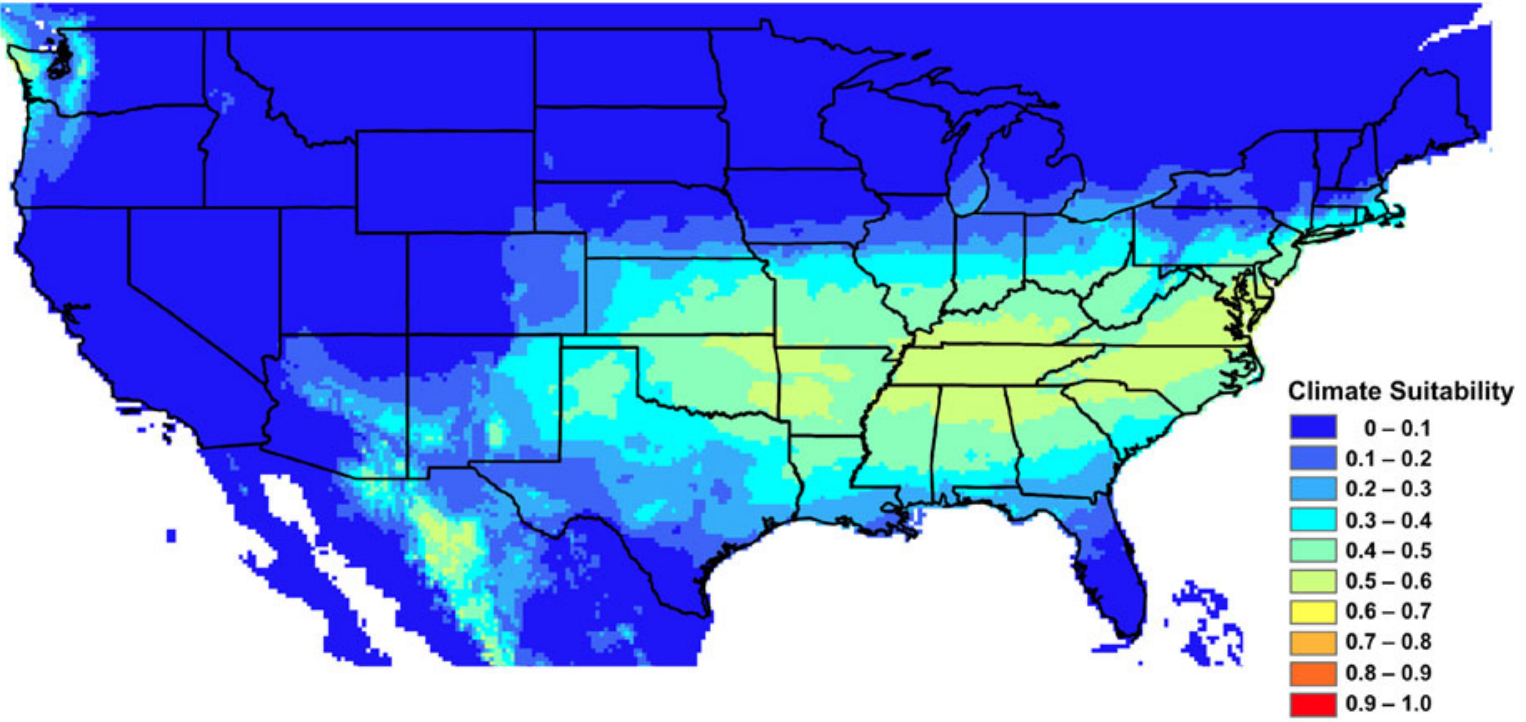

B

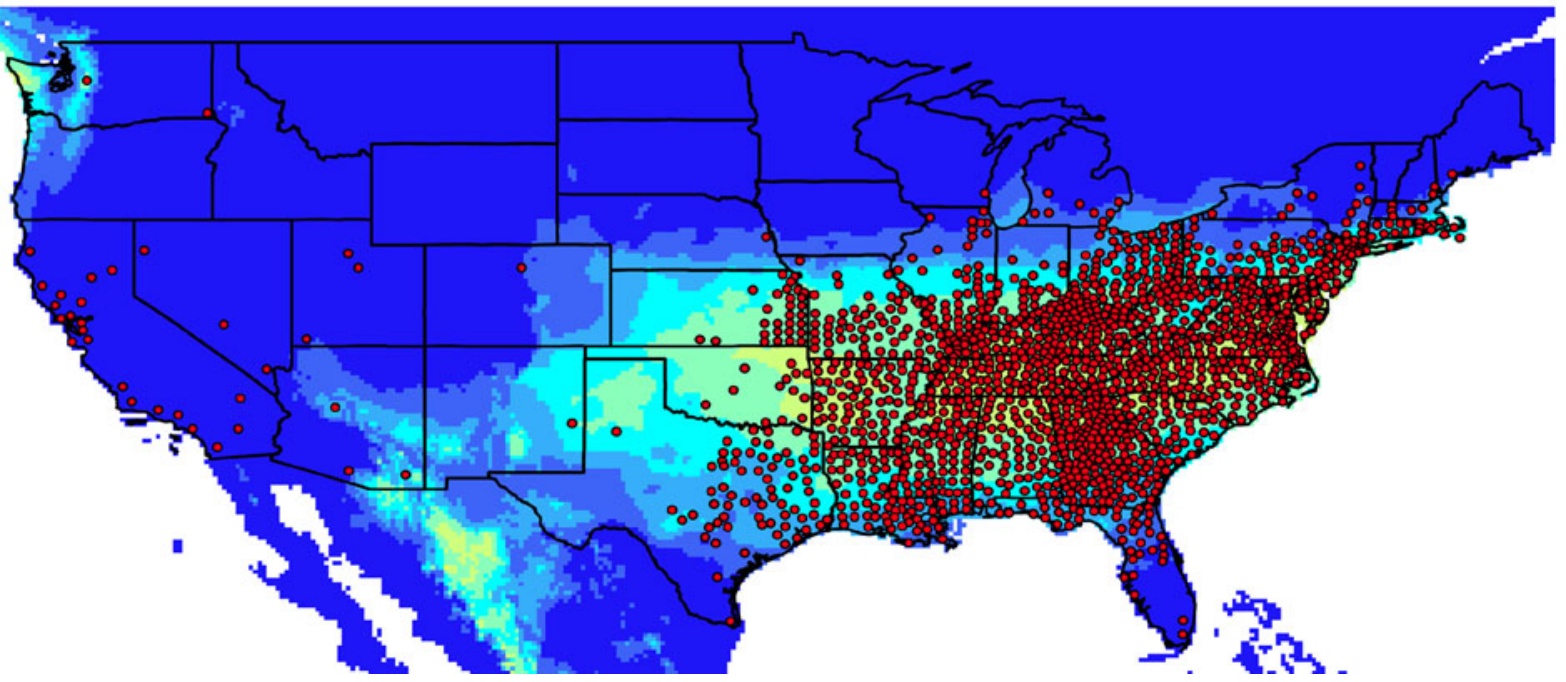

Fig. 1 a MaxEnt native range-trained projection of the potential range of $L$. japonica in the United States using the bioclimatic variables mean temperature of coldest quarter and precipitation of warmest quarter. b Potential range compared

the native range of $L$. japonica to cover most of southeastern China, as well as regions across Japan and South Korea (see Figure S1). The projection had a training AUC value of 0.930 and a test AUC value of 0.932 out of 1 , which strongly supports its predictive power. The test model projected a native range equivalent to that predicted by the training model (not shown). with current range. Warmer colors represent higher climate suitability. Dots mark counties where L. japonica is present. Maps were created using ArcGIS version 9.3.1 (ESRI, Redlands, CA, USA). (Color figure online)
When we projected the model onto the United States the predicted distribution closely matched the current distribution (Wald $\chi^{2} 1,008.34, p<0.0001$, Fig. 1). While we used the subset of climate variables we knew to be most indicative of $L$. japonica survival to train our model, we found that a model trained with all 19 climate variables also closely matched the current distribution (see Figure S2). 
There were a few notable exceptions between our native-range trained models and the current US distribution. The models predicted potential L. japonica growth west of the actual distribution. There appears to be opportunity for populations to establish more densely across the northern edge of the current distribution as well. In the western United States, our models did not project a high suitability for $L$. japonica presence, and yet the actual distribution shows scattered occurrences. Many of these western occurrences fall near cities, which led us to predict that human influence contributes to establishment in these areas.

Identifying variables responsible for current US distribution

All United States-trained models, whether relying on climate variables, the human footprint, or the combination of climate variables and the human footprint, significantly explained the current distribution of $L$. japonica (Table 1). Our full model, which combined all climate variables with the human footprint performed significantly better than the model that relied on climate variables alone (log-likelihood ratio $=$ $37.43, d f=1, p<0.0001)$. The full model also performed significantly better than the model that relied on the human footprint alone (log-likelihood ratio $=2368.58, d f=18, p<0.0001)$. Unlike the native range-trained model, the US-trained models did not predict future range expansion in the United States (data not shown).

The human footprint was an important contributor to the full model. Although variables performed equivalently in the jackknife analysis, the model relied on the human footprint for $11.7 \%$ of gain during training, with only the variables precipitation of driest quarter, annual mean temperature, and precipitation seasonality demonstrating higher contributions

Table 1 Tests of how well predicted distributions explain the current range of Lonicera japonica in the United States

\begin{tabular}{llll}
\hline Candidate models & $\begin{array}{l}-2 \text { log- } \\
\text { likelihood }\end{array}$ & $\begin{array}{l}\text { Wald } \\
\chi^{2}\end{array}$ & $p$ value \\
\hline Climate & $1,509.97$ & 875.07 & $<0.0001$ \\
Human footprint & $3,841.12$ & 361.69 & $<0.0001$ \\
$\begin{array}{l}\text { Climate + human } \\
\text { footprint }\end{array}$ & $1,472.54$ & 838.58 & $<0.0001$ \\
\hline
\end{tabular}

to the training process (Table 2). The human footprint had a permutation importance of $24.7 \%$, higher than any other variable, which indicates that the model loses predictive power when the human footprint values are randomized. The next highest variable was precipitation seasonality at $9.5 \%$ (Table 2 ).

The impact of the human footprint varied across the range of climate suitability values. For the majority of our presence points, the suitability values predicted by the climate-based model were greater than 0.45 (Fig. 2a). For $15 \%$ of our presence points, however, the climate-based model generated low suitability values of below 0.45 . Adding the human footprint significantly increased the predicted suitability of these locations $(t=4.49, d f=233, p<0.0001$; Fig. 2b). However, when the climate-based model predicted a very low suitability value (below 0.15 ), the human footprint did not improve the model (Fig. 2b). Similarly, when climate-based suitability values were above 0.4 , the human footprint did not improve the model, and even slightly reduced the predicted suitability when climate-based suitability values were highest (Fig. 2b).

\section{Discussion}

The native range-trained climate-based model closely predicted the current distribution of Lonicera japonica in the United States. Similar niche modeling studies have also found that the climate conditions in the native range of a species can accurately predict the invaded range (Peterson et al. 2003; Chen et al. 2007). There were, however, some exceptions to the agreement between the projected and current distributions. The native range-trained model predicted further range expansion westward and northward. According to this model, after 200 years of establishment in the US, L. japonica has not yet reached its range limit. Similarly, an analysis of the potential range expansion of the invasive horticultural tree Triadica sebifera (Chinese tallow tree), showed that this species also has the potential to continue to spread in the United States, even after 200 years of invasion (Pattison and Mack 2008). Together these studies indicate that the process of filling the fundamental niche in an invaded range may span centuries. This may especially be true when species' populations invade marginal areas where population growth rates are low. Indeed, the 
Table 2 Estimates of relative contributions of WorldClim climate variables and the human footprint to the explanation of the current distribution of L. japonica in the United States

Percent contribution is the relative contribution of each variable to the United

States-trained model during the model training process.

The permutation

importance is the relative loss in AUC value of the model when the values of a given variable are randomly permuted among the presence points and randomly selected background points (Phillips 2010)

\begin{tabular}{llc}
\hline Variable & $\begin{array}{l}\text { Percent } \\
\text { contribution }\end{array}$ & $\begin{array}{l}\text { Permutation } \\
\text { importance }\end{array}$ \\
\hline Precipitation of driest quarter & 28.8 & 0.4 \\
Annual mean temperature & 27.2 & 4.2 \\
Precipitation seasonality (coefficient of variation) & 13.4 & 9.5 \\
Human footprint & 11.7 & 24.7 \\
Mean temperature of coldest quarter & 4.5 & 8.0 \\
Isothermality & 3.8 & 2.5 \\
Precipitation of driest month & 3.0 & 1.2 \\
Temperature seasonality & 1.8 & 9.1 \\
Min temperature of coldest month & 1.1 & 4.6 \\
Precipitation of wettest quarter & 1.0 & 4.6 \\
Temperature annual range & 0.8 & 1.2 \\
Precipitation of coldest quarter & 0.8 & 9.0 \\
Precipitation of warmest quarter & 0.5 & 1.7 \\
Mean temperature of driest quarter & 0.5 & 3.5 \\
Mean diurnal range (mean of monthly (max temp-min temp)) & 0.3 & 2.8 \\
Max temperature of warmest month & 0.2 & 1.1 \\
Mean temperature of warmest quarter & 0.2 & 4.3 \\
Mean temperature of wettest quarter & 0.2 & 1.7 \\
Precipitation of wettest month & 0.1 & 2.0 \\
Annual precipitation & 0.1 & 3.8 \\
\hline
\end{tabular}

rapid expansion of $L$. japonica early in its North American invasion and the continued, but slower, expansion since, suggests that populations at the margins of the range are encountering conditions near boundaries of their fundamental niche, i.e. extreme cold and low precipitation. However, such boundary conditions may extend over large geographic areas, in which case slow but continued expansion may occur over long time spans.

Our US-trained model showed, however, that climate factors alone do not fully describe L. japonica's distribution in the US. The current US invaded range is largely explained by a combination of climate variables and human influence, with human influence often increasing suitability in regions with suboptimal climates. Human influence likely underlies the failure of the native range-trained climate-based model to predict L. japonica populations scattered throughout urban areas in the western United States. These results agree with a more local-scale niche modeling study of L. japonica which found that its distribution in the Cumberland Plateau and Mountain Region of the United States was in part dependent on anthropogenic activities such as land disturbances (Lemke et al.
2011). Similarly, a niche modeling study of the Peruvian pepper tree (Schinus molle) found that the distance from this invasive tree to planted trees of the same species was more important than climate in explaining its South African distribution (Richardson et al. 2010). This study, like our own, used ecological niche models to show that human influence permits the distribution of a horticultural species beyond favorable climate conditions. Together these results suggest that the portion of an invasive species' projected future range that falls within areas of high human influence is at an elevated risk of future invasion. Additionally, areas outside of this projected future range may also be at risk if human influence is high enough and the climate does not present insurmountable challenges to survival. This finding has implications for the ecological niche modeling of invasive horticultural species, as well as for our understanding of the role of the horticultural industry in species invasions.

Both the climate-based native range-trained model and the climate and human footprint-based US-trained model were necessary for a complete understanding of potential L. japonica range expansion. The native range-trained model was necessary for predicting 
Fig. 2 a Number of $L$. japonica presence points falling within each level of climate suitability.

b Difference $( \pm S E)$ between climate + human footprint suitability and climate suitability for all points where L. japonica is present
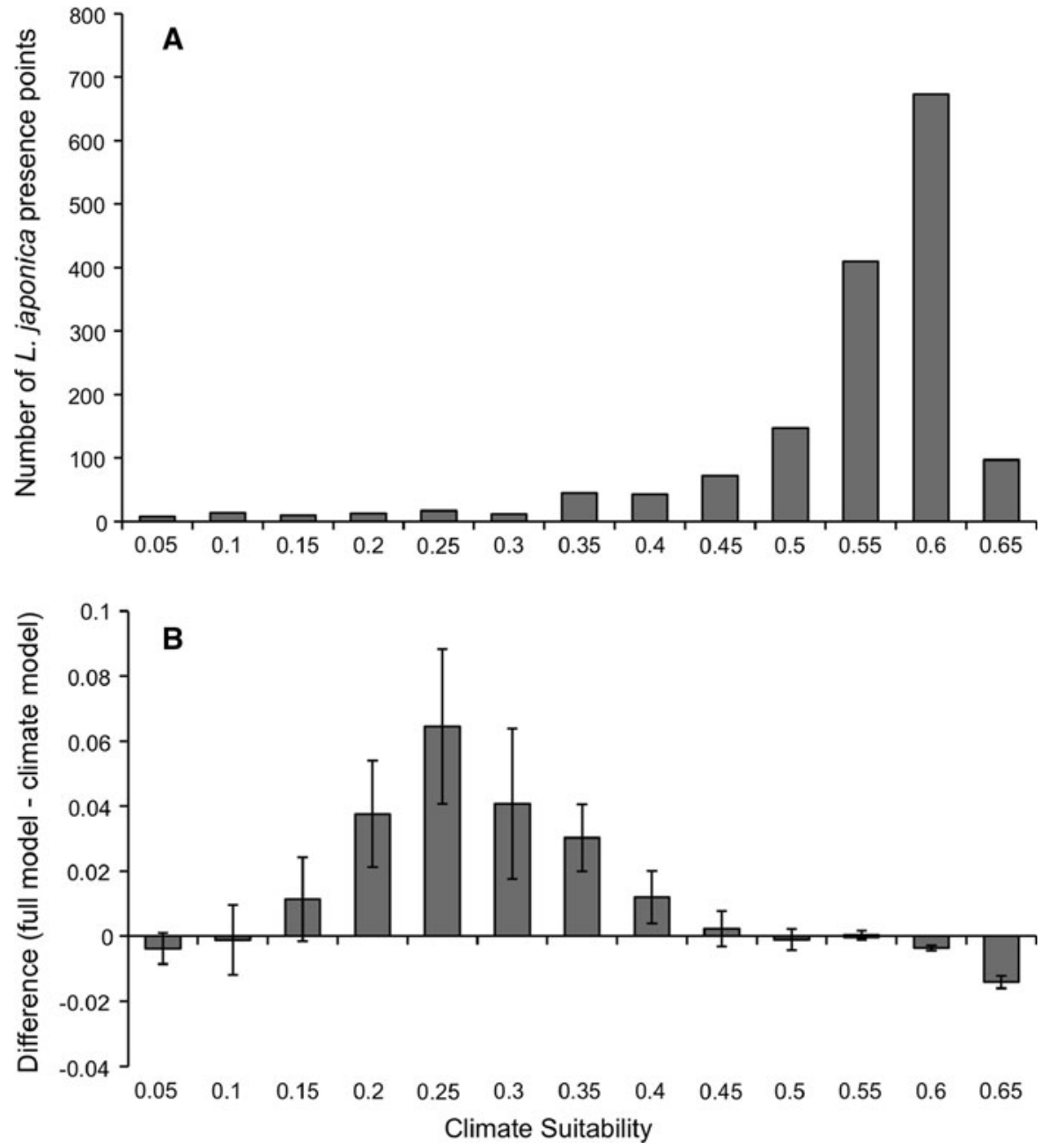

range expansion into suitable climates that have not yet been reached in the United States. It could be used for this prediction because the range of L. japonica in Asia is in equilibrium. As such, the native rangetrained model captured the full spectrum of climate conditions tolerated by the species and so could be used to identify regions with suitable climates in the introduced range where the species has not yet established. The US-trained model cannot be used for this same purpose because L. japonica's range in the United States is likely still expanding (Kilkenny 2011). A US-trained model, therefore, would miss regions with suitable climates if the species has not yet expanded into those areas. On the other hand, the UStrained model was necessary for understanding the role of human influence in determining the current distribution of $L$. japonica in the United States because L. japonica is not used as a horticultural plant in Asia and, therefore, any correlations between human influence and $L$. japonica would not predict the same relationship in the United States.

Because many invasive species' introduced ranges are not yet in equilibrium, and because many invasive species may associate with humans differently in their native and introduced ranges, we suggest that niche modeling studies should consider using both a native range-trained model based on climate and an introduced range-trained model based on climate and human influence. By using both of these techniques, we demonstrated that $L$. japonica has the potential to spread into additional areas with suitable climates and that human influence may increase the chances of 
establishment even in regions beyond suitable climates.

Previous correlational studies have demonstrated close relationships between humans and invasive species richness (Thuiller et al. 2006; Leprieur et al. 2008; Pyšek et al. 2010). Despite this body of evidence suggesting a link between human presence and invasive species, few niche modeling studies have included human influence as a variable in the model (but see Ficetola et al. 2007; Richardson et al. 2010; RouraPascual et al. 2011). The common dependence on climate variables alone stems from the Grinnellian niche concept, which argues that climate suitability is a prerequisite for species presence (Guisan and Thuiller 2005). Under this assumption, more detailed models, which might include factors such as competition, predation, or human influence along with climate, are useful only because they refine the potential range to encompass a more limited space (Guisan and Thuiller 2005). Relying only on climate factors, therefore, would be informative because these models would offer the broadest estimate of a range expansion, and, therefore, alert land managers to the worst possible scenarios.

Our study suggests that given a strong connection with humans, a species may establish in regions deemed suboptimal by a climate-based model. Failing to test for the role of human influence, therefore, may result in the failure to identify areas at risk of invasion. But how is it possible for a species to survive in a supposedly unsuitable climate? Human influence may allow for survival in an otherwise unsuitable climate through propagule pressure and creation of microclimates. Propagule pressure is a combination of the number of introduction events and the number of individuals in each introduction (Lockwood et al. 2005). The greater the popularity of a horticultural plant, the higher the propagule pressure. Propagule pressure may not increase the likelihood of establishment if climate conditions are far beyond the range necessary to satisfy basic needs for survival or reproduction (Ficetola et al. 2009). A constant stream of newly introduced individuals, however, does raise the chances of introducing a rare individual that is capable of producing offspring that can survive in a suboptimal climate outside of the sheltered garden setting. Additionally, propagule pressure may increase the likelihood of introducing genotypes from across the native range that may hybridize and resulting heterosis may allow broader climate tolerance (Suarez and
Tsutsui 2008). For these reasons, propagule pressure has been shown to correlate positively with invasion success (Minton and Mack 2010). Additionally, through land disturbances, humans may create microclimates in an area smaller than the $10^{\prime} \times 10^{\prime}$ scale of this analysis. Clearances for roads, for example, may allow increased sunlight and warmth in an otherwise cooler habitat (Christen and Matlack 2009). Recent research showed that the invasive Argentine ant (Linepithema humile) is capable of establishing in areas with poor climate suitability if human influence creates suitable microclimates (Roura-Pascual et al. 2011). Therefore, through propagule pressure from gardening, and through land disturbances, humans can support the growth of invasive horticultural species in regions beyond their optimal climates.

While horticulture has long been implicated in the spread of invasive species through introductions of cultivars from around the world and marketing across broad geographic regions, our results suggest that it is also capable of extending invasions to geographic areas that would otherwise be unlikely to support establishment (Reichard and White 2001; Pemberton and Liu 2009; Drew et al. 2010). Without active spread and continued propagation by humans, it is highly unlikely that the current range of L. japonica would have reached such a wide distribution, and have extended into so many regions with suboptimal climates. This is likely true, not just for L. japonica, but for many horticultural plants. Multiple estimates suggest that a full $50 \%$ of all naturalized plant species in the United States were intentionally introduced, most of them through horticultural channels (Drew et al. 2010). By preventing the sale of invasive horticultural plants, and educating the public in conscientious gardening practices, we could reduce the rate of range expansion of introduced species, and substantially reduce the spread of these species into areas with less suitable climates. Our findings suggest, therefore, that humans and the horticultural industry as a whole play a larger role in the spread of invasive species than once realized, but we may also have a greater opportunity to prevent further spread than previously believed.

Acknowledgments We thank S. R. Keller for initial guidance on the use of MaxEnt. We also thank D. C. Gist of the University of Virginia's Scholars' Lab for significant assistance with ArcGIS. This manuscript was greatly improved through suggestions from J. Elith and two anonymous reviewers. We also thank D. A. Roach, M. L. Aikens, C. Dai, and K. Barnard- 
Kubow for offering valuable feedback on our manuscript. We thank the following herbaria for information on Lonicera japonica presence in the United States: TAMU, MNA, CMML, TAES, TAC, KANU, COLO, GH, NY, MO, LSU, MUR, BH, VPI, US. Finally, we thank the Jeffress Memorial Trust and the Jefferson Scholars Foundation for financial support.

\section{References}

Chen P, Wiley EO, Mcnyset KM (2007) Ecological niche modeling as a predictive tool: silver and bighead carps in North America. Biol Invasions 9:43-51

Christen DC, Matlack GR (2009) The habitat and conduit functions of roads in the spread of three invasive plant species. Biol Invasions 11:453-465

Dehnen-Schmutz K, Touza J, Perrings C, Williamson M (2007) A century of the ornamental plant trade and its impact on invasion success. Divers Distrib 13:527-534

Dillenburg LR, Whigham DF, Teramura AH, Forseth IN (1993) Effects of below- and aboveground competition from the vines Lonicera japonica and Parthenocissus quinquefolia on the growth of the tree host Liquidambar styraciflua. Oecologia 93:48-54

Drake JM, Bossenbroek JM (2004) The potential distribution of zebra mussels in the United States. Bioscience 54:931-941

Drew J, Anderson N, Andow D (2010) Conundrums of a complex vector for invasive species control: a detailed examination of the horticultural industry. Biol Invasion 12:2837-2851

Dunlop EA, Wilson JC, Mackey AP (2006) The potential geographic distribution of the invasive weed Senna obtusifolia in Australia. Weed Res 46:404-413

Elith J, Phillips SJ, Hastie T, Dudík M, Chee YE, Yates CJ (2011) A statistical explanation for MaxEnt for ecologists. Divers Distrib 17:43-57

Ficetola GF, Thuiller W, Miaud C (2007) Prediction and validation of the potential global distribution of a problematic alien invasive species-the American bullfrog. Divers Distrib 13:476-485

Ficetola GF, Thuiller W, Padoa-Schioppa E (2009) From introduction to the establishment of alien species: bioclimatic differences between presence and reproduction localities in the slider turtle. Divers Distrib 15:108-116

Guisan A, Thuiller W (2005) Predicting species distribution: offering more than simple habitat models. Ecol Lett 8: 993-1009

Hardt RA (1986) Japanese honeysuckle: from "one of the best" to ruthless pest. Arnoldia 46:27-34

Hernandez PA, Graham CH, Master LL, Albert DL (2006) The effect of sample size and species characteristics on performance of different species distribution modeling methods. Ecography 29:773-785

Hijmans RJ, Cameron SE, Parra JL, Jones PG, Jarvis A (2005) Very high resolution interpolated climate surfaces for global land areas. Int J Climatol 25:1965-1978

Kadoya T, Ishii HS, Kikuchi R, Suda S, Washitani I (2009) Using monitoring data gathered by volunteers to predict the potential distribution of the invasive alien bumblebee Bombus terrestris. Biol Conserv 142:1011-1017
Kilkenny FF (2011) Gene flow and adaptation in Lonicera japonica. PhD dissertation, University of Virginia, Charlottesville, VA, USA

Leatherman AD (1955) Ecological life-history of Lonicera japonica Thunb. Dissertation, University of Tennessee, Knoxville, TN, USA

Lemke D, Hulme PE, Brown JA, Tadesse W (2011) Distribution modeling of Japanese honeysuckle (Lonicera japonica) invasion in the Cumberland Plateau and Mountain Region, USA. Forest Ecol Manag 262:139-149

Leprieur F, Beauchard O, Blanchet S, Oberdorff T, Brosse S (2008) Fish invasions in the world's river systems: when natural processes are blurred by human activities. PLoS Biol 6:404-410

Lockwood JL, Cassey P, Blackburn T (2005) The role of propagule pressure in explaining species invasions. Trends Ecol Evol 20:223-228

Lodge DM (1993a) Biological invasions: lessons for ecology. Trends Ecol Evol 8:133-137

Lodge DM (1993b) Species invasions and deletions: community effects and responses to climate and habitat change. In: Karieva PM, Kingsolver JG, Huey RB (eds) Biotic interactions and global change. Sinauer Associates, Sunderland, pp 367-387

McKinney ML (2001) Effects of human population, area, and time on non-native plant and fish diversity in the United States. Biol Conserv 100:243-252

Minton MS, Mack RN (2010) Naturalization of plant populations: the role of cultivation and population size and density. Oecologia 164:399-409

Nuzzo V (1997) Element stewardship abstract for Lonicera japonica. The Nature Conservancy, Arlington

Pattison RR, Mack RN (2008) Potential distribution of the invasive tree Triadica sebifera (Euphorbiaceae) in the United States: evaluating CLIMEX predictions with field trials. Glob Change Biol 14:813-826

Pemberton RW, Liu H (2009) Marketing time predicts naturalization of horticultural plants. Ecology 90:69-80

Peterson AT, Robins CR (2003) Using ecological-niche modeling to predict barred owl invasions with implications for spotted owl conservation. Conserv Biol 17:1161-1165

Peterson AT, Papes M, Kluza DA (2003) Predicting the potential invasive distributions of four alien plant species in North America. Weed Sci 51:863-868

Phillips SJ (2008) Transferability, sample selection bias and background data in presence-only modelling: a response to Peterson et al. (2007). Ecography 31:272-278

Phillips SJ (2010) A brief tutorial on MaxEnt. Lesson Conserv 3:107-135

Phillips SJ, Anderson RP, Schapire RE (2006) Maximum entropy modeling of species geographic distributions. Ecol Model 190:231-259

Pyšek P, Jarošík V, Hulme PE, Kühn I, Wild J, Arianoutsou M, Bacher S et al (2010) Disentangling the role of environmental and human pressures on biological invasions across Europe. Proc Natl Acad Sci USA 107:12157-12162

Reichard SH, White P (2001) Horticulture as a pathway of invasive plant introductions in the United States. Bioscience 51:103-133

Richardson DM, Iponga DM, Roura-Pascual N, Krug RM, Milton SJ, Hughes GO et al (2010) Accommodating 
scenarios of climate change and management in modeling the distribution of the invasive tree Schinus molle in South Africa. Ecography 33:1-13

Roura-Pascual N, Hui C, Ikeda T, Leday G, Richardson DM, Carpintero S, Espadaler X et al (2011) Relative roles of climatic suitability and anthropogenic influence in determining the pattern of spread in a global invader. Proc Natl Acad Sci USA 108:220-225

Sanderson EW, Jaiteh M, Levy MA, Redford KH, Wannebo AV, Woolmer G (2002) The human footprint and the last of the wild. Bio Sci 52:891-904

Schierenbeck K (2004) Japanese honeysuckle (Lonicera japonica) as an invasive species; history, ecology, and context. Crit Rev Plant Sci 23:391-400

Skulman BW, Mattice JD, Cain MD, Gbur EE (2004) Evidence for allelopathic interference of Japanese honeysuckle (Lonicera japonica) to loblolly and shortleaf pine regeneration. Weed Sci 52:433-439

Suarez AV, Tsutsui ND (2008) The evolutionary consequences of biological invasions. Mol Ecol 17:351-360
Sullivan JJ, Williams PA, Cameron EK, Timmons SM (2004) People and time explain the distribution of naturalized plants in New Zealand. Weed Technol 18:1330-1333

Thuiller W, Richardson DM, Rouget M, Procheş Ş, Wilson JRU (2006) Interactions between environment, species traits, and human uses describe patterns of plant invasions. Ecology 87:1755-1769

Urban MC, Phillips BL, Skelly DK, Shine R (2007) The cane toad's (Chaunus [Bufo] marinus) increasing ability to invade Australia is revealed by a dynamically updated range model. Proc R Soc B 274:1413-1419

USDA (2009) Natural resources conservation service plants profile, Lonicera japonica thunb. [WWW document] URL http://plants.usda.gov/java/profile?symbol=LOJA

Wang R, Wang Y (2006) Invasion dynamics and potential spread of the invasive alien plant species Ageratina adenophora (Asteraceae) in China. Divers Distrib 12:397-408

Ward DF (2007) Modelling the potential geographic distribution of invasive ant species in New Zealand. Biol Invasion 9:723-735 
Figure S1. MaxEnt native range-trained, climate-based projection of the native range of $L$. japonica using $75 \%$ of presence points as training data. Warmer colors represent higher climate suitability. Red dots mark L. japonica presence. Map was created using ArcGIS version 9.3.1 (ESRI, Redlands, CA, USA).

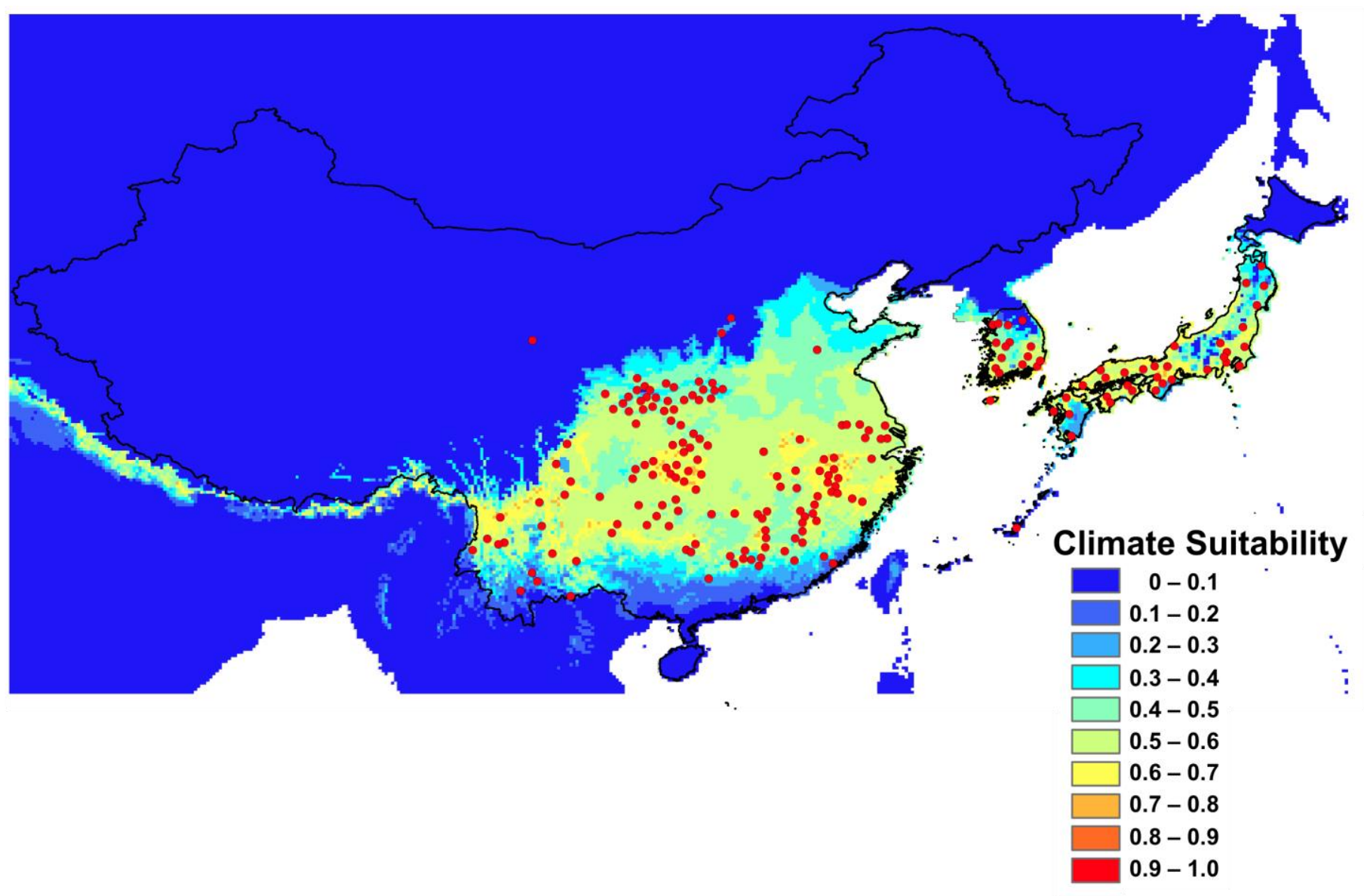


Figure S2. A) MaxEnt native range-trained projection of the potential range of L. japonica in the United States using all climate variables. B) Potential range compared with current range. Warmer colors represent higher climate suitability. Red dots mark counties where L. japonica is present. Maps were created using ArcGIS version 9.3.1 (ESRI, Redlands, CA, USA).
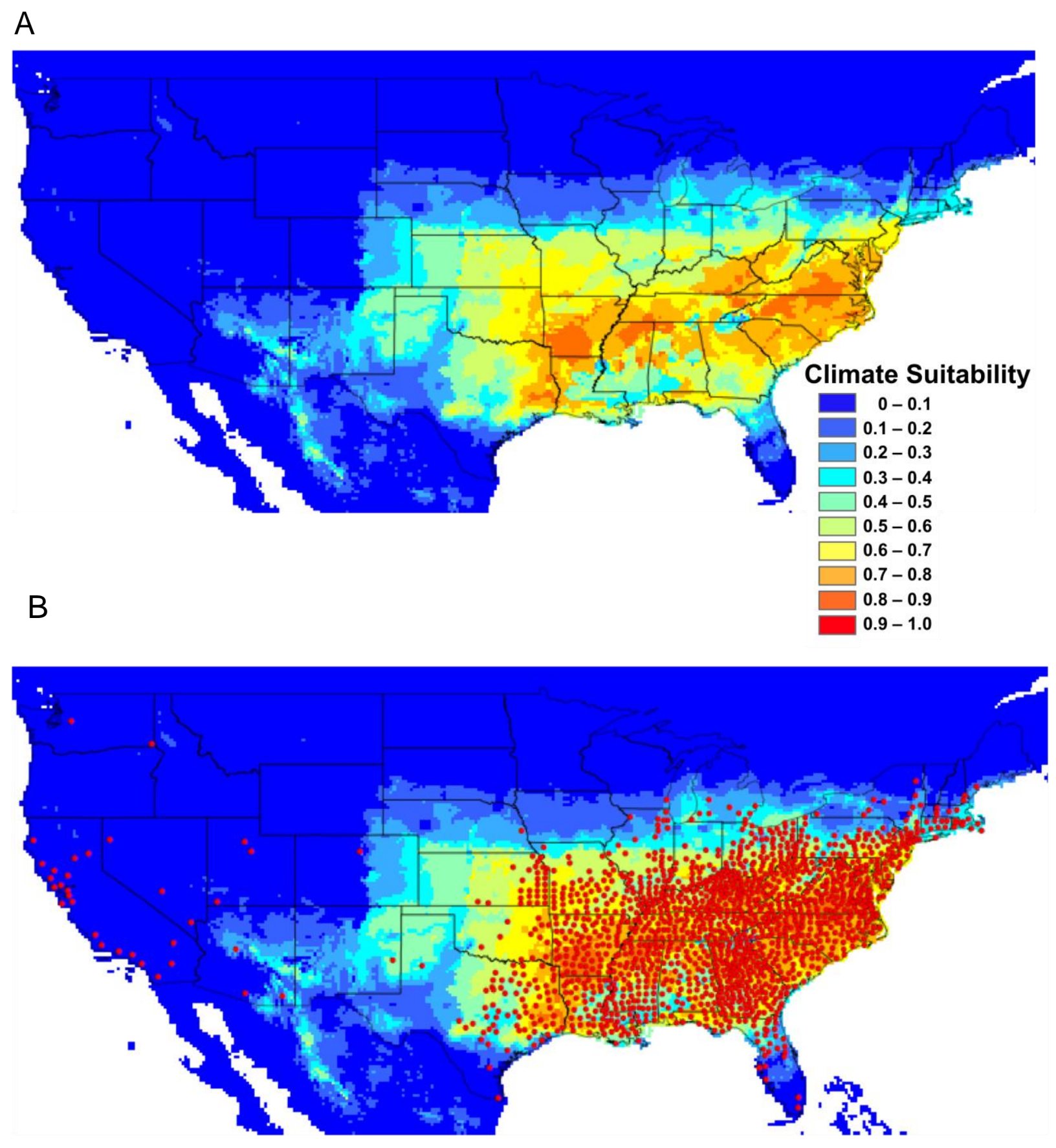
1 Table S1. Direct collections, online databases and herbaria accessed for L. japonica locality information.

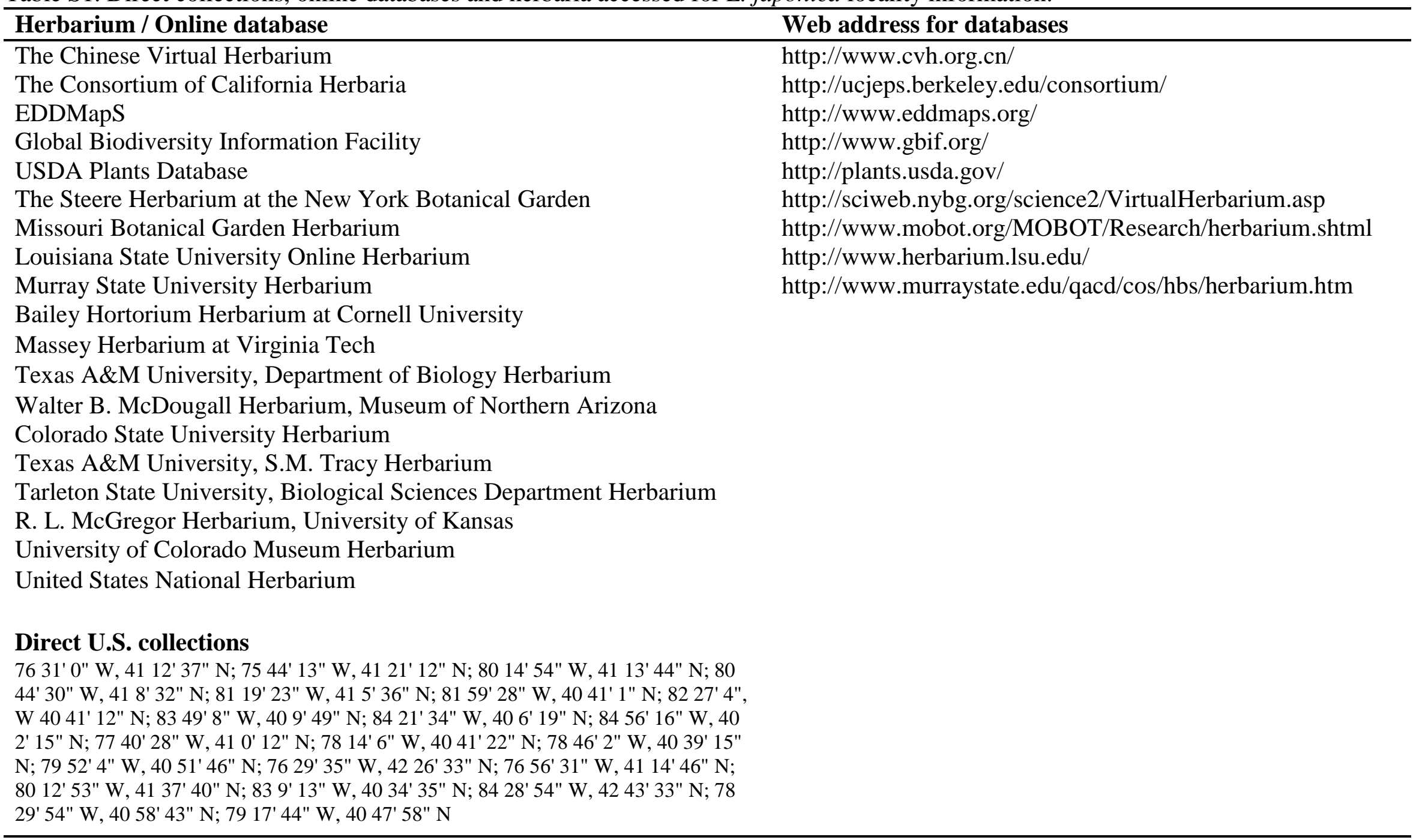


5 Table S2. Climate variable and human footprint correlations (R) for the United States.

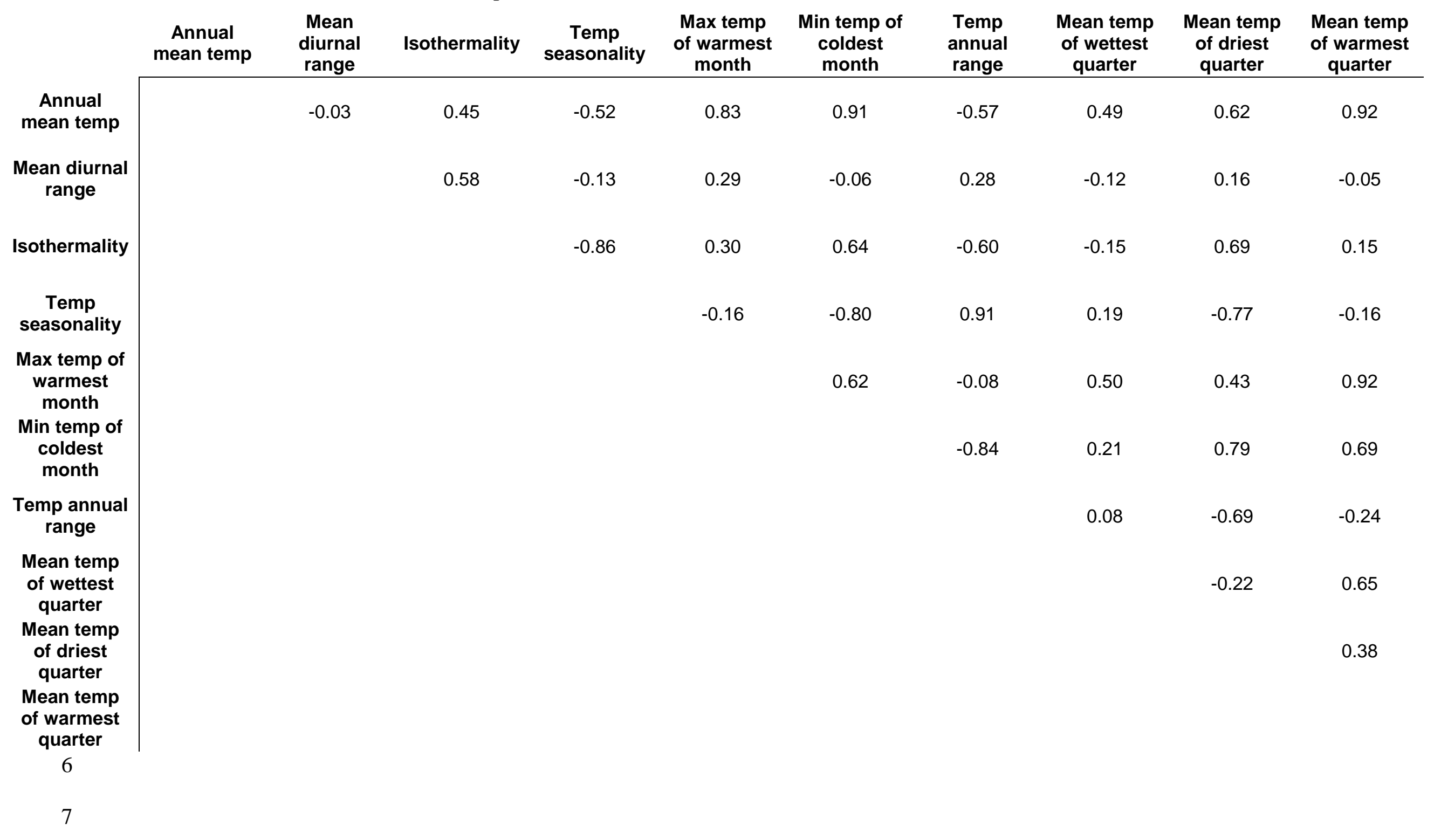


8 Table S2. Continued.

\begin{tabular}{|c|c|c|c|c|c|c|c|c|c|c|}
\hline & $\begin{array}{l}\text { Mean temp } \\
\text { of coldest } \\
\text { quarter }\end{array}$ & $\begin{array}{l}\text { Annual } \\
\text { precip }\end{array}$ & $\begin{array}{c}\text { Precip of } \\
\text { wettest } \\
\text { month }\end{array}$ & $\begin{array}{l}\text { Precip of } \\
\text { driest } \\
\text { month }\end{array}$ & $\begin{array}{l}\text { Precip } \\
\text { seasonality }\end{array}$ & $\begin{array}{c}\text { Precip of } \\
\text { wettest } \\
\text { quarter }\end{array}$ & $\begin{array}{c}\text { Precip of } \\
\text { driest } \\
\text { quarter }\end{array}$ & $\begin{array}{c}\text { Precip of } \\
\text { warmest } \\
\text { quarter }\end{array}$ & $\begin{array}{l}\text { Precip of } \\
\text { coldest } \\
\text { quarter }\end{array}$ & $\begin{array}{l}\text { Human } \\
\text { Footprint }\end{array}$ \\
\hline $\begin{array}{c}\text { Annual } \\
\text { mean temp }\end{array}$ & 0.94 & 0.30 & 0.27 & 0.29 & -0.03 & 0.23 & 0.31 & 0.27 & 0.22 & 0.30 \\
\hline $\begin{array}{l}\text { Mean diurnal } \\
\text { range }\end{array}$ & 0.06 & -0.68 & -0.59 & -0.55 & 0.35 & -0.60 & -0.57 & -0.60 & -0.45 & -0.47 \\
\hline Isothermality & 0.68 & -0.09 & 0.02 & -0.13 & 0.22 & 0.00 & -0.12 & -0.34 & 0.22 & -0.21 \\
\hline $\begin{array}{c}\text { Temp } \\
\text { seasonality }\end{array}$ & -0.77 & -0.28 & -0.33 & -0.19 & 0.05 & -0.31 & -0.22 & 0.11 & -0.54 & 0.01 \\
\hline $\begin{array}{l}\text { Max temp of } \\
\text { warmest } \\
\text { month }\end{array}$ & 0.70 & -0.13 & -0.14 & -0.05 & 0.14 & -0.18 & -0.05 & 0.00 & -0.20 & 0.13 \\
\hline $\begin{array}{l}\text { Min temp of } \\
\text { coldest } \\
\text { month }\end{array}$ & 0.99 & 0.38 & 0.37 & 0.32 & -0.08 & 0.34 & 0.35 & 0.14 & 0.45 & 0.24 \\
\hline $\begin{array}{l}\text { Temp annual } \\
\text { range }\end{array}$ & -0.76 & -0.57 & -0.56 & -0.44 & 0.19 & -0.55 & -0.48 & -0.18 & -0.71 & -0.21 \\
\hline $\begin{array}{c}\text { Mean temp } \\
\text { of wettest } \\
\text { quarter }\end{array}$ & 0.28 & 0.07 & 0.07 & 0.08 & 0.12 & 0.04 & 0.07 & 0.49 & -0.27 & 0.26 \\
\hline $\begin{array}{l}\text { Mean temp } \\
\text { of driest } \\
\text { quarter }\end{array}$ & 0.77 & 0.20 & 0.16 & 0.21 & -0.14 & 0.15 & 0.23 & -0.17 & 0.45 & 0.05 \\
\hline $\begin{array}{l}\text { Mean temp } \\
\text { of warmest } \\
\text { quarter } \\
9\end{array}$ & 0.75 & 0.18 & 0.13 & 0.22 & 0.00 & 0.09 & 0.23 & 0.33 & -0.01 & 0.33 \\
\hline
\end{tabular}


10 Table S2. Continued.

\begin{tabular}{|c|c|c|c|c|c|c|c|c|c|c|}
\hline & $\begin{array}{l}\text { Mean temp } \\
\text { of coldest } \\
\text { quarter }\end{array}$ & $\begin{array}{l}\text { Annual } \\
\text { precip }\end{array}$ & $\begin{array}{l}\text { Precip of } \\
\text { wettest } \\
\text { month }\end{array}$ & $\begin{array}{l}\text { Precip of } \\
\text { driest } \\
\text { month }\end{array}$ & $\begin{array}{l}\text { Precip } \\
\text { seasonality }\end{array}$ & $\begin{array}{l}\text { Precip of } \\
\text { wettest } \\
\text { quarter }\end{array}$ & $\begin{array}{l}\text { Precip of } \\
\text { driest } \\
\text { quarter }\end{array}$ & $\begin{array}{l}\text { Precip of } \\
\text { warmest } \\
\text { quarter }\end{array}$ & $\begin{array}{l}\text { Precip of } \\
\text { coldest } \\
\text { quarter }\end{array}$ & $\begin{array}{l}\text { Human } \\
\text { Footprint }\end{array}$ \\
\hline $\begin{array}{l}\text { Mean temp } \\
\text { of coldest } \\
\text { quarter }\end{array}$ & & 0.30 & 0.30 & 0.27 & -0.03 & 0.27 & 0.29 & 0.13 & 0.35 & 0.19 \\
\hline $\begin{array}{l}\text { Annual } \\
\text { precip }\end{array}$ & & & 0.90 & 0.82 & -0.42 & 0.91 & 0.85 & 0.72 & 0.84 & 0.45 \\
\hline $\begin{array}{l}\text { Precip of } \\
\text { wettest } \\
\text { month }\end{array}$ & & & & 0.52 & -0.05 & 0.99 & 0.57 & 0.58 & 0.84 & 0.35 \\
\hline $\begin{array}{l}\text { Precip of } \\
\text { driest } \\
\text { month }\end{array}$ & & & & & -0.75 & 0.53 & 0.99 & 0.71 & 0.58 & 0.43 \\
\hline $\begin{array}{c}\text { Precip } \\
\text { seasonality }\end{array}$ & & & & & & -0.07 & -0.75 & -0.37 & -0.26 & -0.22 \\
\hline $\begin{array}{l}\text { Precip of } \\
\text { wettest } \\
\text { quarter }\end{array}$ & & & & & & & 0.57 & 0.58 & 0.85 & 0.36 \\
\hline $\begin{array}{l}\text { Precip of } \\
\text { driest } \\
\text { quarter }\end{array}$ & & & & & & & & 0.72 & 0.62 & 0.44 \\
\hline $\begin{array}{l}\text { Precip of } \\
\text { warmest } \\
\text { quarter }\end{array}$ & & & & & & & & & 0.27 & 0.48 \\
\hline $\begin{array}{l}\text { Precip of } \\
\text { coldest } \\
\text { quarter }\end{array}$ & & & & & & & & & & 0.25 \\
\hline $\begin{array}{l}\text { Human } \\
\text { Footprint }\end{array}$ & & & & & & & & & & \\
\hline
\end{tabular}


Beans, Kilkenny and Galloway 7

11 